\title{
Towards Wholeness and Integrity of Distributed Dynamic Systems
}

\author{
Peter Simon Sapaty* \\ National Academy of Sciences of Ukraine, Kiev, Ukraine
}

\section{Introduction}

In an addition to the variety of topics listed in the Aims and Scope of the Journal of Computer Science and Systems Biology, we want to offer here some more areas within its general orientation which could encourage extended research and paper submissions. These especially relate to efficient organization of large distributed dynamic systems of diverse natures which may require innovative, even revolutionary, solutions reflecting the growing world dynamics in the 21 st century.

We are witnessing a dramatic change in the character of national and international activity, especially in crisis and conflict areas, with the use of asymmetric, unconventional, and hybrid solutions. They may simultaneously involve economy, ecology, international relations, ethnicity, culture, law, religion, etc., defense and military too, occupying both physical and virtual environments. These solutions may need to be holistic, multidimensional, and highly integral in order to succeed.

The aim of this message is not to present new research or implementation results in a particular field but rather introduce and popularize some important directions which could extend the benefits of symbiosis between ideas of computer science and biology under the general banner of wholeness and integrity of large distributed systems, including new technologies for their effective management and control.

\section{Current Management Philosophy: Interoperability}

Interoperability [1-3] is a quality of a system with understood and clear interfaces to work with other systems without restrictions. There may be different kinds of interoperability. Syntactic interoperability means that two or more systems are just capable to communicate with each other. Semantic interoperability supposes that beyond the ability to exchange information, different systems are capable of interpreting the exchanged information. Cross-domain interoperability occurs is when different kinds of entities (which may be multiple social, organizational, political, legal, etc.) can work together for a common purpose.

Interoperability is the key principle at present for joint operations in both civil and military areas. For example, NATO has been based on interoperability since 1949 when it was founded. Interoperability allows organizations of different nationalities and armed services to conduct joint peacekeeping operations. Interoperability is also dominant in any international relief missions acting after natural or manmade disasters.

\section{The Interoperability Insufficiency}

Increased complexity of operations due to growing world dynamics and emerging instability makes existing interoperability principles not fully sufficient to provide the needed overall awareness, integrity, and pursuit of global goals, with runtime adjustment to new ones. The situations are often complicated by the necessity to operate in cyber-contested multi-dimensional spaces with high connectivity and inter-dependence, also with numerous actors having own, often quite different purposes and interconnections.

We are often witnessing failures of interoperability-based systems on international levels, where seemingly honest and noble intensions and actions of different players to improve complex situations in certain places on the globe may lead to quite unexpected results. This occurs by not grasping the current and future whole of the problem properly, and especially by the lack of adequate scientific and technological means for its expression and managing.

On the way to increase integrity and wholeness of distributed systems and missions, we may already have a background and support from well-known system theories and approaches which try to consider complex systems as holistic organisms rather than collection of communicating parts defined independently. A brief description of some of them follows.

\section{System Dynamics}

Fundamental works have been carried out by Jay Forrester on analysis of complex systems (urban, industrial, world as whole) and their detailed computer simulation [4-7]. It has become clear that complex systems are counterintuitive, where corrective actions are often ineffective or even adverse in the results.

In complex systems the cause and the effect are often not closely related in either time or space, and their structure is not a simple feedback loop. In reality, complex system has a multiplicity of interacting feedback loops, and its internal rates of flow are controlled by nonlinear relationships. Complex systems are usually of high order, with many system states or levels. They may contain positive-feedback loops reflecting growth, and negative, goal-seeking ones. In the complex system the cause may lie far back and away from symptoms, and the causes are usually found not in prior events but rather in the structure and policies of the system.

\section{Biology-Related General Systems Theory}

This theory after Ludwig von Bertalanffy [8-10] is based on similar general conceptions and viewpoints which have emerged and evolved in various disciplines. In the past, science tried to explain observable phenomena by reducing them to communication and interplay of elementary units which are independent from each other.

New approaches are based on what is termed "wholeness," where systems of various orders cannot be understood, even in principle, by investigation of their parts in isolation. Conceptions of this nature have appeared in all branches of science, regardless of which types of objects are being studied (i.e., inanimate things, living organisms, social phenomena, etc.).

*Corresponding author: Peter Simon Sapaty, National Academy of Sciences of Ukraine, Kiev, Ukraine, Tel: 380674199224; E-mail: peter.sapaty@gmail.com

Received May 20, 2016; Accepted May 25, 2016; Published May 30, 2016

Citation: Sapaty PS (2016) Towards Wholeness and Integrity of Distributed Dynamic Systems. J Comput Sci Syst Biol 9: e112. doi:10.4172/jcsb.1000e112

Copyright: (c) 2016 Sapaty PS. This is an open-access article distributed under the terms of the Creative Commons Attribution License, which permits unrestricted use, distribution, and reproduction in any medium, provided the original author and source are credited. 


\section{Gestalt Psychology}

Gestalt is both philosophy and psychology term which means unified whole [11-15]. It refers to visual perception theories developed by German psychologists at the beginning of the past century. These theories tried to understand and describe how people can organize visual elements into groups or unified wholes under certain conditions and principles, maintaining our meaningful perceptions in an apparently chaotic world.

Forming a global whole with self-organizing tendencies is being the central principle of gestalt psychology, where the whole has a reality of its own, independent of the parts, and our brain can generate whole forms, visually recognizing global figures instead of just collections of simpler and unrelated elements (like points, lines, curves, etc.).

\section{Integral Psychology}

The integral psychology $[16,17]$ is determined to embrace and unite all aspects of human consciousness under one concept, integrating ideas and models of consciousness, psychology, and therapy. The resultant psychological model includes waves of development, streams of development, states of consciousness, and the self. Under existing general consensus, neither mind nor brain can be reduced without each other, which means that both mind and brain need to be included in a non-reductionistic way in any integral theory of consciousness.

\section{Memetics}

Memetics [18-21] is the theory of mental content based on an analogy with Darwinian evolution. Being an emerging subfield of psychology, memetics is considered as an approach to evolutionary models of cultural information transfer. The meme, analogous to a gene, was conceived as a "unit of culture" (like idea, belief, pattern of behavior, etc.) which is "hosted" in the minds of one or more individuals, and which can reproduce itself, jumping from mind to mind.

Memes spread through the social body similar to how genes spread through the biological body, forming the invisible DNA of human society. Much like a virus moves from body to body, memes move from mind to mind. Memetics can be effectively used to identify and target specific root causes of challenging social problems in different areas; military memetics is being developed as its branch too.

\section{Human Terrain}

Whereas geographic terrain, or merely terrain, is used to represent vertical and horizontal dimensions of land surface, human terrain [2225] deals with human population, its culture and interactions, being a new and rapidly growing field of research originated, as a term, from military operations.

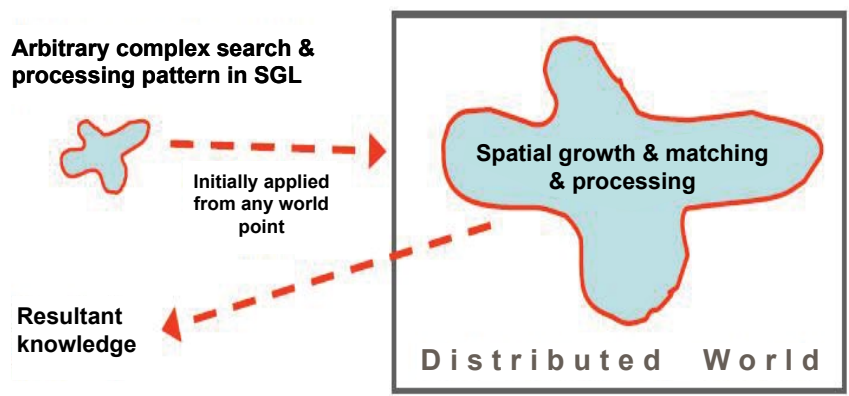

Figure 1: How SGT operates in general.
All local and global conflicts are about people: their behaviors, attitudes, fears, social structures, family and ideological ties and narratives. Understanding the human dimensions of conflict is therefore a critical determinant in preventing conflicts, shaping them and influencing the actors involved. It contributes to strategic awareness, ability to plan and execute operations, helps to identify threats and opportunities.

Human terrain is defined as characterizing cultural, anthropological, and ethnographic information about the human population and interactions within the operations area. Human terrain analysis is the process through which understanding of the human terrain is developed. It integrates human geography and cultural information.

\section{Our Own Contribution to the Area}

We have developed an approach called over-operability [25-29], in both opposition and extension to the interoperability, which allows for integral global-goal-driven solutions in distributed environments. This approach uses creatively the ideas briefed in the previous sections 4 to 9. The resultant Spatial Grasp Technology (SGT) with Spatial Grasp Language (SGL) as its key element has been prototyped and tested with numerous researched applications. In the most general terms it operates as shown in Figure 1.

A high-level scenario for any task in a distributed world is represented as an integral and active self-evolving pattern rather than traditional program, sequential or parallel. This pattern, expressing top semantics and key decisions of the problem to be solved spatially propagates, replicates, modifies, covers and matches the world, creating distributed operational infrastructures throughout it, with the final results retained in the environments or returned as high level knowledge to the starting point.

SGL directly operates with physical, virtual and executive words and their any combinations. It has a universal recursive structure shown in Figure 2. Such organization allows us to express any spatial algorithm, create and manage any distributed structures and systems, static or dynamic, passive or active, also solve any problem in, on, and over them, and this can be expressed in a compact, transparent, and unified way (Figure 2).

The paradigm developed has been investigated and used to find highly integral solutions in distributed dynamic systems, including the ones related to collective behavior of large numbers of cooperating robotic units, critical infrastructures investigation, creation and

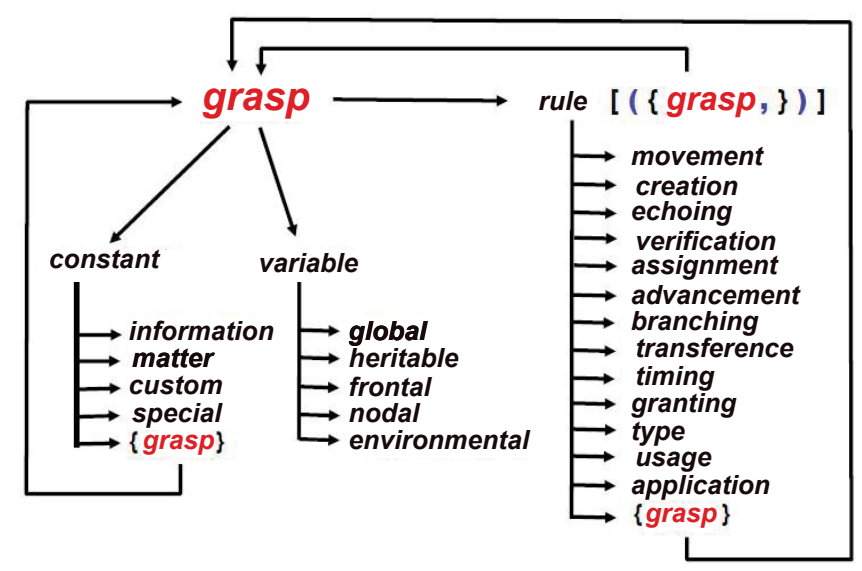

Figure 2: SGL recursive syntax. 
Citation: Sapaty PS (2016) Towards Wholeness and Integrity of Distributed Dynamic Systems. J Comput Sci Syst Biol 9: e112. doi:10.4172/ jcsb.1000e112

protection, automated up to fully automatic command and control, advanced maritime operations, spatial intelligence, missile defense, night vision, and many others. More on this can be found in the recent publications in the current journal $[30,31]$, also in the earlier books $[32,33]$.

SGT allows us to describe and implement integral spatial solutions on a variety of levels and their mixtures, including topmost semantic ones, where high-level mission scenarios reflecting main operations and decisions can always survive, and by any means, whereas particular system components, their numbers and interactions, also overall management and control can change at runtime, automatically adjusting to the rapidly changing goals and environments.

\section{Conclusions}

New ideas, research and implementation results on wholeness and integrity of large distributed dynamic systems (including from the briefed fields) are much welcome at the Journal of Computer Science and Systems Biology, which are of great need nowadays in numerous areas related to (just named only a few) economy, ecology, demographics, education, infrastructure protection, security, crisis management, and defense. We will be providing all needed encouragement and support for their development, comprehensive analysis, and quick publication.

\section{References}

1. Wikipedia (2016) Interoperability. Accessed on: May 2016.

2. Slater T (2012) What is Interoperability? Network Centric Operations Industry Consortium-NCOIC.

3. NATO (2006) Interoperability for joint operations. Accessed on: July 2006.

4. Forrester J (1969) Urban Dynamics. Pegasus Communications, MIT Press, USA.

5. Forrester J (1971) World Dynamics. Wright-Allen Press, USA.

6. Forrester J (1961) Industrial dynamics. Waltham, MA: Pegasus Communications, MIT Press, USA.

7. Forrester $J(2009)$ Learning through system dynamics as preparation for the 21st century. USA.

8. Bertalanffy L (1968) General System Theory Foundations, Development, Applications. George Braziller, New York, USA.

9. Bertalanffy L (1950) The Theory of Open Systems in Physics and Biology. Science 2872: 23-29

10. Bertalanffy $L$ (1951) Theoretical Models in Biology and Psychology. Journal of Personality 20: 24-38.

11. https://en.wikipedia.org/wiki/Gestalt_psychology.

12. Wagemans J, Elder JH, Kubovy M, Palmer SE, Peterson MA, et al. (2012) A Century of Gestalt Psychology in Visual Perception: I. Perceptual Grouping and Figure-Ground Organization. Psycho Bullet 138: 1172-1217.

13. Wertheimer M (1923) Untersuchungen zur Lehre von der Gestalt II: Prinzipielle Bemerkungen. Psychologische Forschung 4: 301-350.

14. Köhler W (1920) Die physischen Gestalten in Ruhe und im stationären Zustand Eine natur-philosophische Untersuchung. Braunschweig: Friedr. Vieweg and Son, Germany.

15. Koffka K (1935) Principles of Gestalt psychology. Lund Humphries, London, UK

16. Wilber K (2003) Waves, Streams, States, and Self: An Outline of an Integral Psychology. Human Psychol 31: 22-49.

17. Wilber K (2000) Integral Psychology: Consciousness, Spirit, Psychology, Therapy. Shambala Publications, Boston, USA.
18. Dawkins R (1976) The Selfish Gene. Oxford University Press, UK.

19. Wikipedia (2016) Memetics. Accessed on: May 2016.

20. Hancock BJ (2010) Memetic Warfare: The Future of War. Military Intelligence 36: 41-46.

21. Finkelstein R (2011) Tutorial: Military Memetics. Robotic Technology Inc.

22. Gonzalez R (2008) Human terrain: Past, present and future applications. Anthropology Today 24: 21-26.

23. Jacob K, Lester GL, Prinslow K, Smith D (2006) The Human Terrain System: A CORDS for the 21st century. Defense Technology Information Center (DTIC).

24. Joint Doctrine Note 4/13, Culture and Human Terrain (2013). Accessed on: May 2016.

25. Sapaty P (2014) Distributed Human Terrain Operations for Solving National and International Problems. Int Rel Diplo 2: 2328-2134.

26. Sapaty $P(2002)$ Over-Operability in Distributed Simulation and Control. The MSIAC's M\&S Journal Online 4: 1-7.

27. Sapaty P (2008) Grasping the Whole by Spatial Intelligence: A Higher Level for Distributed Avionics. Proc international conference Military Avionics 2008, Café Royal, London, UK.

28. Sapaty P (2009) Gestalt-Based Integrity of Distributed Networked Systems. SPIE Europe Security + defence, bcc Berliner Congress Centre, Berlin, Germany.

29. Sapaty $P$ (2015) Providing Over-operability of Advanced ISR Systems by a High-Level Networking Technology. SMl's Airborne ISR, 26th to 27th October 2015, Holiday Inn Kensington Forum, London, United Kingdom.

30. Sapaty P (2016) Towards Massively Robotized Systems under Spatial Grasp Technology. Journal of Computer Science \& Systems Biology 9: 69-75.

31. Sapaty P (2016) A Brief Introduction to the Spatial Grasp Language (SGL). Journal of Computer Science \& Systems Biology 9: 76:92.

32. Sapaty P (2005) Ruling Distributed Dynamic Worlds. John Wiley \& Sons, New York, USA.

33. Sapaty $P$ (1999) Mobile Processing in Distributed and Open Environments John Wiley \& Sons, New York, USA. 